\title{
Beyond the Fourfold Gospel
}

A Critical Reading of Francis Watson's Gospel Writing: A Canonical Perspective Omerzu, Heike

Published in:

Journal for the Study of the New Testament

DOI:

10.1177/0142064X14557603

Publication date:

2014

Citation for published version (APA):

Omerzu, H. (2014). Beyond the Fourfold Gospel: A Critical Reading of Francis Watson's Gospel Writing: A Canonical Perspective. Journal for the Study of the New Testament, 37(2), 201-209.

https://doi.org/10.1177/0142064X14557603 


\title{
Beyond the Fourfold Gospel: A Critical Reading of Francis Watson's Gospel Writing: A Canonical Perspective
}

Journal for the Study of the New Testament 20I4, Vol. 37(2) 20I-209

(C) The Author(s) 2014 Reprints and permissions: sagepub.co.uk/journalsPermissions.nav DOI: 10.1 I77/0I42064XI4557603 jsnt.sagepub.com

@SAGE

\section{Heike Omerzu}

University of Copenhagen, Denmark

\begin{abstract}
This article discusses Francis Watson's fresh approach to the origins of gospel writing. In general, Watson's attempt to revisit the history of the Synoptic Problem by questioning $\mathrm{Q}$ and integrating non-canonical writings is greatly appreciated. Some questions are, however, raised regarding, for instance, the extent to which Luke made use of Matthew or the existence of a Christian 'Sayings Collection' genre. It is argued that an explanation of the Synoptic Problem demands a more complex theory than the one sketched by Watson and that the question of manuscript transmission also needs to be integrated into that theory.
\end{abstract}

\section{Keywords}

Sayings Source Q, Sayings Collection genre, gospel origins, fourfold gospel, noncanonical writings, historical Jesus

What is remarkable about Francis Watson's Gospel Writing is not only its breadth and erudition, but also the fact that it presents a really fresh approach to understanding the origins of gospel writing. Watson engages with canonical and noncanonical gospels, as well as early Christian literature, art and liturgy, in order to describe and discuss the emergence of the fourfold gospel. Along the way he refutes the existence of the Sayings Source Q and sets out a good argument in support of an initially lively interaction between gospels that later became known

\section{Corresponding author:}

Heike Omerzu, Faculty of Theology, Department for Biblical Exegesis, University of Copenhagen,

Købmagergade 44-46, Postbox 2I64, I I 50 Copenhagen K, Denmark.

Email: ho@teol.ku.dk 
as either canonical or apocryphal. Due to the limitation of space I will focus mostly in this article on issues related to the so-called Synoptic Problem, while not, for instance, being able to discuss Watson's intriguing reading of Reimarus's reception by Albert Schweitzer ${ }^{1}$ or the implications of canonization for the interpretation of the fourfold gospel. ${ }^{2}$

Watson vehemently questions what he calls the 'standard account' of gospel origins, which suggests that the four canonical gospels emerged one after the other during the last third of the first century CE. This account, it is argued, fails 'to grasp that canon formation presupposes a process of reception' (p. 3) and is not identical with the process of composition: 'Selection is subsequent to production' (p. 3). Watson therefore calls for a 'paradigm shift' (p. 2) that entails an account which provides 'a more comprehensive framework' (p. 3) and reconstructs 'a precanonical situation in which gospel writing constitutes a single dynamic field as yet undivided by the canonical decision' (p. 7). His thesis is that it is 'to be expected that gospels later deemed canonical were at first intimately related to gospels later passed over, and that all kinds of intertextual connections may still be discerned in spite of the canonical boundary. Against this background, the fourfold gospel may itself be seen as an act of gospel production, marking the defining moment in the reception-history of the individual texts it contains while also establishing a new, composite text which generates a more comprehensive reception-history of its own' (p. 7).

This is the agenda that Watson forcefully implements in the volume at hand. His approach has to be regarded as an innovative and important attempt at revisiting the history — not only but especially — of the Synoptic Problem by questioning Q and integrating some of the so-called apocryphal gospels that (mostly) were not yet known when the 'standard account' of the formation of the fourfold gospel was established. In a tour de force extending from Augustine through the Enlightenment to the twentieth century, Watson traces literary explanations for the Synoptic Problem and shows how the Two Source theory was developed. Q came to be esteemed as 'pure primal gospel as proclaimed by Jesus himself, rather than the gospel about Jesus proclaimed by the early church' (p. 117). Thus, the quest for $\mathrm{Q}$ became an important means for the quest of the historical Jesus.

Engagement with the history of research is an important part of Watson's reasoning as he, to my mind convincingly, demonstrates that many arguments in support of Q cannot in fact be substantiated. Watson himself advocates the theory that Luke knew and used both Mark and Matthew (designated by Watson, and in what follows, as the $L / M$ theory). ${ }^{3}$ Watson states: 'To establish the likelihood that Luke is the interpreter of Matthew means establishing the unlikelihood

1. 'Reimarus's true narrative function is to prefigure Schweitzer himself' (p. 66).

2. Cf. Part 3 of Gospel Writing.

3. Cf. pp. 118-19. 
of the Q theory' (p. 119). Watson correctly notes that one of the main challenges for this enterprise is the history of research: 'That Q still represents a default position for New Testament scholarship is not just the result of institutional inertia or methodological conservatism. Simply, Q has had better and more compelling advocacy than the rival theories' (p. 119). The immediate reaction to this observation might be that $\mathrm{Q}$ has actually had the more convincing arguments on its side. Yet, Watson is correct in his observation that the main presupposition for $\mathrm{Q}$ is the independence of Matthew and Luke: 'Any item that Luke takes from Matthew is taken away from Q' (p. 120). ${ }^{4}$ Watson scrutinizes this crucial issue and claims that the " $\mathrm{Q}$ theory is based on a long series of coincidences, which extend far beyond the "minor agreements" as normally defined ... The question $\ldots$ is whether the coincidences are too many and too striking for Luke's independence of Matthew to remain plausible' (pp. 121-22). ${ }^{5}$ Examples of such occurrences are the simultaneous yet independent composition of Matthew and Luke, their independent use of Mark as the backbone of both narratives, the independent use of Q to supplement the Markan plot, and the fact that both Matthew and Luke include unique material and add birth narratives and genealogies at the beginning and resurrection stories at the end of their gospels. Watson justly draws the conclusion: 'If these parallels are anything other than coincidental, there is no Q' (p. 131).

Many of the examples listed by Watson in Chapter 3 ('The Coincidences of Q') are quite compelling and, by and large, he convincingly argues that the Q theory operates with far more problems than those commonly designated as 'minor agreements'. I do, however, have reservations regarding some of the arguments used to support Luke's use of Matthew. My questions concern, for instance, the fundamental differences (which are also acknowledged by Watson [cf. p. 132]) between the infancy narratives and the appearances stories in Matthew and Luke. I cannot discuss Watson's exegesis in detail here and will only draw attention to one example regarding the annunciation stories, where he contends that 'Luke's narrative works so well as the obverse of Matthew's that it

4. Less convincing is the subsequent argument that 'if Luke can be shown to take even a single item from Matthew, he may also have taken others from the same source' (p. 120). This reasoning underestimates the possibility that Luke might have had several other sources at hand, written or oral, that are not known to us. I will return to this point later.

5. Watson's starting-point is an analysis of Luke's prologue and Papias's statement on Matthew (pp. 121-31): '[T]he two gospels known to Papias are likely to have been the earliest. There is no indication in either Papias or Irenaeus that Matthew and Luke were written at much the same time, as the Q theory must suppose. Papias testifies directly to Markan priority and indirectly, in conjunction with Irenaeus, to the priority of Mark and Matthew over Luke' (p. 128). I do not find convincing Watson's reading of either of the two texts, but they are also not necessary for his argument. They rather serve his rhetoric to question the existence of $\mathrm{Q}$ and to establish the possibility of an interdependence between Matthew and Luke. 
is hard not to conclude that it was intended as such' (p. 135). This conclusion is, to my mind, an argumentum ex silentio and as hypothetical as the foundation of the Q hypothesis. Instead of seeking similarities between Matthew and Luke (i.e., 'major agreements' commonly identified as Q) Watson bases his argument on dissimilarities. This procedure involves an even higher degree of uncertainty, not least because Watson more or less rejects the possibility that Luke also depends on non-Matthaean traditions (p. 136 n. 46). Unless one reckons with a very high degree of authorial freedom on Luke's side, which does not accord with the concept conveyed in the prologue (which, incidentally, serves as an important part of Watson's argument), we have to expect that Luke had access to (oral or written?) infancy and appearance traditions that differed from Matthew's traditions. That Luke, like Matthew, incorporated these materials respectively at the beginning and end of his gospel is unsurprising and might but need not have been inspired by Matthew. Notwithstanding this criticism, Watson's overall intention to demonstrate that Luke actually knew Matthew is convincing. 'In reality, there is far-reaching agreement in the incorporation of additional material into the Markan framework from the preaching of John the Baptist and the temptation narrative to the Inaugural Sermon' (pp. 154-55). However, one might have to determine the nature of the relationship more precisely. In other words, even if Luke knew Matthew, this does not mean that he always used Matthew.

In Chapter 4 ('Luke the Interpreter') Watson argues his case from the opposite side by presupposing that $\mathrm{Q}$ did not exist and by demonstrating how Luke drew on Matthew. Luke's use of Matthew is divided into three categories (cf. pp. 15859): material that is adapted (i.e., rephrased or elaborated), material that is rejected (i.e., not included in Luke), material that is reserved (i.e., used at a later stage in Luke's narrative). The last category of reserved material is regarded as the 'main key to reconstructing Luke's compositional procedure' (p. 159), and Watson makes a good case for Luke's editorial procedures on the basis of the $L / M$ theory (for instance, the use of Mt. 5-7 [cf. pp. 163-68]): Luke's 'selection, rearrangement, and composition are motivated by the intention to interpret the sayings material rather than simply reproducing it in mechanical fashion' (p. 164). At the same time he refutes, amongst others, the 'spurious argument that Luke ought to have reproduced the Sermon on the Mount in more or less its Matthean form, and that he would have done so as a matter of course if he had been familiar with it' (p. 175). Watson rightly points out that this reasoning is based on the later dignified, canonical status of the Sermon on the Mount, ${ }^{6}$ and can thus not be regarded as a valid argument. Besides, it presupposes a modern reader's logic and expectation that might not necessarily be identical with the implied or real reader's reasoning.

6. See also the conclusion on pp. 215-16. 
Watson focuses in general on examining the question of whether either the Q theory or the assumption of Luke's dependence on both Mark and Matthew $(L / M$ theory) provides the best solution to the Synoptic Problem, thereby consciously ignoring other alternatives: 'It goes without saying that other theories are also possible in principle-Matthean dependence on Luke, perhaps, or (more plausibly) a "complexity hypothesis" according to which synoptic origins were in reality too complex for us to be able to reconstruct' (p. 137) As much as a concise and simple answer to the Synoptic Problem is desirable, a 'complexity hypothesis' might actually be the more appropriate solution. In fact, some of Watson's general concerns might be integrated into such a hypothesis, especially his claim to set aside the canonical border when discussing the early period of gospel formation.

That the origins of gospel writing are more multifaceted than is outlined by both the 'standard account' and the $L / M$ theory can actually be supported by Watson's subsequent line of argumentation. In Chapter 5 ('Thomas versus Q') he rightly states that the canonical recognition of the fourfold gospel 'represents the construction of a new textual object, rather than a passive acknowledgment of what should have been obvious to all' (p. 217). It thus has to be problematized that the "so-called "synoptic problem" is constructed entirely within the space marked out by the canon' (p. 218). There is no reason to assume that the gospels later recognized as canonical in fact originated in complete isolation from those that came to be recognized as non-canonical. Watson therefore holds that the Gospel of 'Thomas preserves certain formal characteristics of the primitive Christian Sayings Collection (SC), a genre that predated the synoptic gospels and that remained important throughout the second century' (p. 221). As Thomas is analysed 'in the light of its genre ... [and] no primitive Christian SC can be recovered from later redaction' (p. 221), Watson holds that 'it is arguable that Thomas preserves isolated items ... in their oldest accessible form' (p. 221). Furthermore, he assumes that the Sayings Collection genre was known to, and used by, the synoptic gospels (cf. p. 250). His solution to the Synoptic Problem is therefore as follows: 'To the $L / M$ hypothesis, which replaces Q, a Thomasbased SC hypothesis may be added. The two hypotheses are independent yet mutually reinforcing' (p. 251).

As I have reservations regarding the details of the $L / M$ theory (as sketched above), the same applies to the SC theory but for different reasons. First, apart from Thomas, Watson cannot provide sufficient and real examples to prove the existence of an SC genre. His main witness is 2 Clement, where repeatedly the same introductory formula is used as in Thomas: 'Jesus says/said' (pp. 252-53). This has to be regarded as quite weak evidence, especially because 2 Clement as a whole represents a different genre from Thomas, which implies that the examples are taken out of their original context. Another witness adduced to support the existence of an SC genre is the Gospel to the Egyptians as attested by Clement of Alexandria (cf. pp. 257-58); in addition, Watson refers to a few other 
fragments or quotations by Christian writers who, it is claimed, attest to the genre of Sayings Collection (e.g., P. Oxy, 1 Clement, Justin, Polycarp, Origin; cf. pp. 262-71). On the basis of these references, Watson makes far-ranging assumptions regarding the SC genre: In addition to 'the use of standardized introductory formulae ... SCs contain (i) short individual utterances, without context; (ii) juxtapositions in which one utterance serves to interpret another; (iii) responses to questions, requests, or remarks; (iv) passages of more extended dialogue; (v) extensions of a saying by addition of formally similar units' (p. 262). He even draws conclusions regarding the Sitz im Leben of SCs and holds that they were not intended to be formally read during worship but served as an 'additional textual resource for preaching' (p. 272).

Mark 4 is adduced as proof of the early dating of the SC genre:

[B]oth Mark and Thomas contain versions of the Parable of the Sower. If an early SC is in principle a plausible source for the Markan version of the parable, then the existence of this parable in a later SC may be cited as evidence for this source-critical hypothesis (pp. 273-74).

This argument is inaccurate because Watson earlier admits that 'Thomas is apparently dependent on Matthew and Luke for parts of its content' (p. 249; see also the scheme on reception processes [p. 347] to which reference is made further below). If that is the case, it is impossible to decide which came first, the chicken or the egg, Mk 4 or an SC/Thomas version of the parable. In fact, Watson proceeds here in a way similar to the one for which the supporters of the $\mathrm{Q}$ theory are reproached: independence is held up to prove a source-critical theory and thus becomes part of a circular argument. This becomes obvious when Watson recapitulates this part of his argument:

Thomas, then, is the point of departure for an 'SC hypothesis' that should replace the implausible Q hypothesis. GTh itself is best understood as a descendant of the early SCs employed by Mark and Matthew, and as a relation of SCs known from second-century sources. The early SCs cannot be reconstructed as a whole; unlike Q, there can be no 'critical edition'. Yet items in GTh with synoptic parallels can plausibly be traced back to presynoptic collections. Even where a saying in its present form betrays the influence of synoptic redaction, that may be the result of secondary assimilation (p. 284).

According to Watson, Luke was less dependent on SCs than Mark and Matthew since he had two other gospels at hand. However, as I have already mentioned, I find it likely that Luke drew on more traditions than those preserved in Mark and Matthew. If Watson's theory is correct, namely, that an SC genre existed from early on and throughout the first centuries, it should be regarded as likely that Luke also had access to it and that some of the material that the $L / M$ theory designates as 'Matthean' was directly taken over by Luke from such a collection. 
Similar questions can be raised about the reconstruction of reception processes as sketched in the following chapters of Gospel Writing. Chapter 6 deals with the relationship between the Gospel of John and the Egerton Gospel and Watson supposes that the Egerton Gospel can be regarded as a Johannine source: 'The Egerton fragments make it possible to recover a theological trajectory away from the Jesus/Moses issue that so preoccupied Christian Jews, towards ever more radical formulations of Jesus' relation to God' (p. 340). However, here also Watson has to operate with arguable assumptions, such as the notion of several layers of John and certain readings that are rendered 'more likely' than others. At the beginning of Chapter 7 ('Reinterpreting in Parallel [Jn, GTh, GPet]') Watson unfolds his model of reception processes 'extending from the life of Jesus to the formation of the fourfold canonical gospel' (p. 342). This is illustrated by a chart where, in each case, 'the analysis begins from an extant text (Matthew, Luke, Thomas, John) and postulates dependence on a prior text (Mark, Matthew, GHeb, proto-John) which may itself be dependent on a precursor (an SC, a collection of miracle stories, GEger)' (p. 343). Watson himself admits that the '[i]ntermediate and primary stages can often be identified only tentatively and approximately. There is no question of large-scale reconstructions of entire texts or text forms, as is sometimes attempted for Q or the Johannine Sign Source' (pp. 343-44). While the aim is not to identify an original text, this model implies a high degree of uncertainty. Besides, Watson follows in the footsteps of the supporters of the 'standard account' insofar as he bases his thesis (apart from SC) mostly on extant texts, whereas it seems more likely to reckon with other, no longer available texts during the beginnings of gospel writing. Furthermore, it is surprising that Watson concludes that 'the oldest accessible form may be said to approximate to the original written form and to represent it' (p. 344). The notion of the relative stability of traditions conflicts somewhat with earlier attempts to describe the process of rewriting and reception based as it is on identifying differences. ${ }^{8}$

While I appreciate the critical review of what Watson designates as the 'standard account' of gospel origins, I do not find his proposal of an 'alternative account' to be fully convincing. This is partly due to the fact that the alternative hypotheses are very speculative. Another caveat relates to the implicit purpose connected to the diachronic approach applied by Watson. Theoretically he questions - to my mind appropriately - the viability of source-critical hypotheses: 'It is arguable, and indeed plausible, that the narrative-critical perspective represents a long overdue liberation of the gospels from captivity to source-critical hypotheses' (p. 157).

7. Cf., for instance, p. 315: 'It is not impossible that such an emphasis might be post-Johannine, in which case the aim is to reverse the trajectory of the source text. But it is more likely to be pre-Johannine.'

8. Cf., for instance, p. 156: 'The hypothesis of dependence makes it possible to describe a difference between two evangelists as a modification'. 
However, the diachronic approach practically favoured by Watson is justified by the disputable argument that a narrative-critical perspective reduces Jesus to the mere 'protagonist in a narrative' (p. 157). This remark is surprising because Watson is fully aware that "the "real", historically- and theologically-significant Jesus cannot be detached from the process of reception' (p. 157), and yet he holds that 'a diachronic account of the reception process (so far as this is accessible to us) may serve to clarify the relationship between the flesh-and-blood Jesus of Nazareth and the figure embodied in the texts' (p. 157). To my mind, all that Watson's approach can achieve is a comparison between the Jesus figure in different texts or traditions. Also, in other respects Gospel Writing is characterized by an ambiguity between its radically new and conservative positions. On the one hand, Watson holds a critical stance towards the so-called 'standard account' and supports the inclusion of non-canonical writings when exploring the history of gospel origins. On the other hand, he exhibits an interest in connecting the early traditions with the historical Jesus, which is exactly what he criticizes the supporters of the Q theory of doing:

To dispense with $\mathrm{Q}$ is also to abandon the fruitless quest for an original uninterpreted object and to attend instead to the dynamic of tradition (p. 158).

Above all, Q in its various forms has to do with the movement behind problematic canonical gospels that seeks a more secure point of access to the life of Jesus. Q represents a movement against the diachronic flow of the early Christian tradition in which the life of Jesus is interpreted, in quest of an uninterpreted Jesus (pp. 102-103).

Watson rightly states that, in this respect, nothing will be won by replacing one source-critical theory with another.

However, Watson also makes assumptions regarding the oral stage of the tradition and relates it to the idea of "a collective knowledge or "social memory" (p. 345). This concept is not explored in detail but becomes closely related to authoritative figures such as the Twelve, and it is ultimately connected to the historical Jesus:

The oral tradition presupposed in the gospels is the social memory of the general and the particular in the life of Jesus. That memory is initially constructed within the earliest Christian communities in Jerusalem, Judea, and Galilee ... Those who recollect are above all the leaders of the earliest community, who have attained their leadership roles precisely because of their prior relationship with Jesus and their authoritative recollection of what he said and did (pp. 346-47).

The process of reception, according to Watson, follows the order: datum $\rightarrow$ recollection $\rightarrow$ tradition $\rightarrow$ inscription $\rightarrow$ interpretation $\rightarrow$ reinterpretation $\rightarrow$ normativization (p. 347). This construct is very optimistic and almost exclusively 
based on gospel material, thereby neglecting the earliest written Christian texts, the Pauline letters, as well as competing models of the emergence of early Christianity. Although Watson emphasizes the 'mediated character of all knowledge of Jesus' (p. 8) throughout the volume, he holds that interpretation not only moves towards instead of away from Jesus, but even engages the idea of ipsissima verba:

Yet interpretation does not overwhelm the original textual datum, subsuming the person of Jesus into that of his interpreter. SCs and their users repeatedly insist that a given saying proceeds from the mouth of Jesus ... and that it is therefore to be understood as his own utterance. An original act of communication from Jesus to ourselves is the foundation of all ongoing communicative action within the Christian community (p. 273).

As it can no longer be determined what the original act of communication looked like - as also admitted by Watson earlier in the book - is there not at the heart of his work the same historical quest for Jesus as that for which the Q theory is criticized?

Earlier I advocated, albeit without providing much detail, a complexity theory to replace the Q theory. To my mind such a theory should not only reckon with missing links, i.e. traditions and texts that are no longer available to us and cannot be reconstructed, but also with text transmission as a crucial factor in the reception history of the extant texts, especially during an early stage of gospel writing. The manuscripts upon which Watson bases his argument derive mostly from a time when the four gospel collection was - in practice - established. One has, in other terms, to take into account even more unknown factors. This is not unimportant in light of Watson's interest in the fourfold canonical gospel as a 'new text':

The analogy is not exact; the fourfold gospel adds no new textual material but reorders material that already exists. Yet the reordering has hermeneutical consequences so profound that here too one must speak of a new text, more than and other than the sum of its parts (p. 453).

This is an important observation that does, nevertheless, underestimate the significance of text transmission as reconstructed by text criticism. It should also, in other words, be considered that the 'standard' text of the canonical gospels came down to us in manuscripts that derive from the period after the canonical divide.

In spite of my reservations regarding the details of the $L / M$ theory, the Sayings Collection genre and the possibility to trace back traditions to an original 'datum', I want to emphasize that I greatly appreciate Watson's elaborate critique of traditional source criticism and his attempt to accommodate both the process of canonization and non-canonical writings into his 'fresh account' of gospel origins. 